\title{
The Weak-sided Urban Fringe and the Flexible Planning Approaches
}

\section{a case study of strategic plan of Yuhuatai District, Nanjing}

\author{
Zhao CHEN, Urban Planner; China \\ Chunxiao Huang, Associated Professor; China
}

\begin{abstract}
Although urban fringe is regarded as a unified academic concept, the actual development results present a strong divergence into two categories: the strongsided urban fringe and the weak-sided urban fringe. This paper starts from basic concept of the weak-sided urban fringe based on existing theory and summarizes the features of the weak-sided urban fringe according to empirical cases, including the low-quality, collage-style land use mode, the structural shortage of both core resources and fundamental facilities, and the fragmented spatial governance. Secondly, differing from the development of strong-sided urban fringe with high investment, urban sprawl and self-replication dominated by growth machines during the rapid urbanization period, this paper proposes the weak-sided urban fringe should adopt a flexible planning approach characterized by precise input, structural optimization and organic growth. Finally, taking the example of Strategic Plan of Yuhuatai District, this paper initially discusses the methodology of flexible planning, including repair of embedded structures, action-oriented organic regeneration and the organizational optimization of multi-governance systems guided by planning.
\end{abstract}

\section{Keywords}

Urban Fringe, Unbalanced Growth, Flexible Planning

\section{Unbalanced Growth in Urban Fringe: The Propose of weak-sided Fringe}

During the rapid urbanization of China in the past 40 years, the urban fringe area has undergone high-speed dynamic changes and has become the most important growth carrier for China's cities. Studies on China's urban fringe in recent years has achieved fruitful results have construct a preliminary theoretical framework from urban fringe's concepts and characteristics to economic, social, ecological, demographic dynamics and mechanisms, as well as corresponding planning issues and approaches.

When systematically browsing scientific literature on subjects related to China's urban fringe, one main research bias can be identified that more attention is paid to the benchmarking or pilot fringe areas with better development results and more distinctive features. The similarity of this kind of urban fringe is often located in the dominant direction of urban spatial expansion or the main regional traffic corridor, and therefore become the city's key 
development area that undertakes core resources, forming a series of successful mode including residential new town, university town, economic development zone and airport city. This paper argues that the growth of urban fringe in most China's cities is unbalanced and despite the above mentioned 'strong-sided' fringe, urban fringe on the 'weak' side should not be ignored. Weak-sided fringe are usually located in the direction that deviated from the main direction of the city and hence incapable to attract high-quality functions and core resources, resulting in a clear gap compared with the strong-sided one. However, both existing researches and planning cases on urban fringe areas are unconsciously concentrated on the strong-side urban fringe while researches on the weak-side urban fringe area are insufficient, and the experiences of strong-side urban fringe cannot be replicated to the weak-sided one.

The conception of urban fringe was first proposed by Hebert Louts in 1936 based on his observation of the urban structure of Berlin. Louts found that the original rural area was gradually occupied by the urban construction and hence became part of the city. Robert Park and E. W. Burges generalized the city into the concentric zone model with CBD at the centre and the transitional urban fringe as the intermediate ring between urban and rural area. Hoyt further modified the concentric zone model account for the impact of transportation systems on accessibility enhancement brought by major transportation routes (e.g. metropolitan expressways and interstate highways). Hoyt theorized that cities would tend to grow in sectors patterns, emanating from the CBD and centred on major transportation routes. Higher levels of access translate to higher land values. Thus, many activities and functions would develop in a wedge surrounding transport routes.

Hoyt's model is also accord with the realties in China's cities. However, the establishment mechanism is slightly different from the spontaneous emerging process as Hoyt observed in U.S., but is formed through active planning regulation. In order to achieve the balance between the growth efficiency and the environmental conservation in the early stage of suburbanization and to avoid the development dissipation and ecological erosion due to the spontaneous sprawl, the municipal government intentionally concentrate the resources and investment in certain part of urban fringe, or the prior development zone, while the rest are regulated as ecological corridor, agricultural zone or restricted development zone. In other words, the emergence of strong-sided/weak-sided fringe is the not only decided by the fringe's relationship with transportation, but also the will of the municipal government.
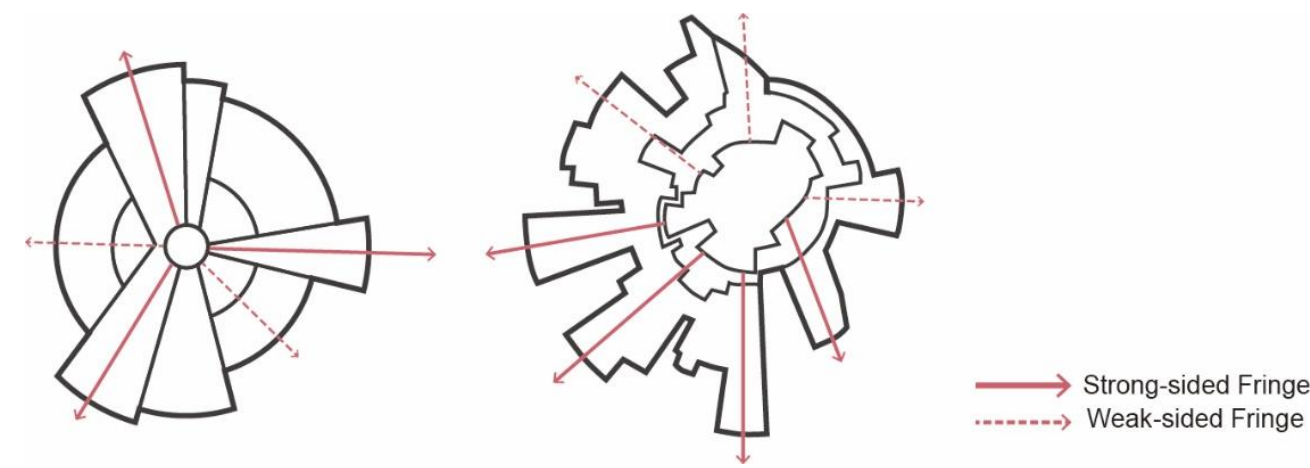

Figure 1 Hyot's sector model(left) and the nonequilibrium growth of urban fringe in Shanghai 


\section{History and Reality of the Weak-sided urban fringe: evidences from Yuhuatai}

\subsection{Historic trace: mega-project driven urbanization}

As mentioned above, the intention of government played an important role in making the weak-sided fringe. Looking back in history, Yuhuatai District has long been regarded as the periphery outside the city in the government's plan, and therefore presents a typical exogenous urbanization pattern, whose driven power is not the spontaneous agglomeration of citizens, but the implanted mega-project initiated by the government.

After the founding of new China, the central government began to implement the heavy industries leap-forward strategy and anti-urbanism strategy. At that time the state-owned enterprise, or Danwei is more than a productive unit but a self-sufficient, isolated and closed small society for 'the working class', and is usually located away from the cities. As for Yuhuatai, it is firstly recognized in the $1960-70$ s as the concentration area of giant stateowned steel and mining enterprises for its deep-water harbour and appropriate distance with the city. And it became the initial driving force of the development of Yuhuatai.

After the opening and reform, exogenous industrialization and rapid urbanization process become the engine economic growth in China in the 1990, whose key contents are inter-city competition on attracting FDI and land financing mechanism. In 2000s, Yuhuatai District became the agglomeration of different types of public housing projects for its exploitable land low land price. Most of the housing projects are the removal settlement for the former peasantry whose land and houses in the land expropriation (land financing), and the rest are the indemnificatory housings for the low-income citizens. In 2010, it began to Governmentled software Industrial Park for foreign and domestic IT companies, focusing on software outsourcing service, serving companies in Silicon Valley, Israel or Ireland.

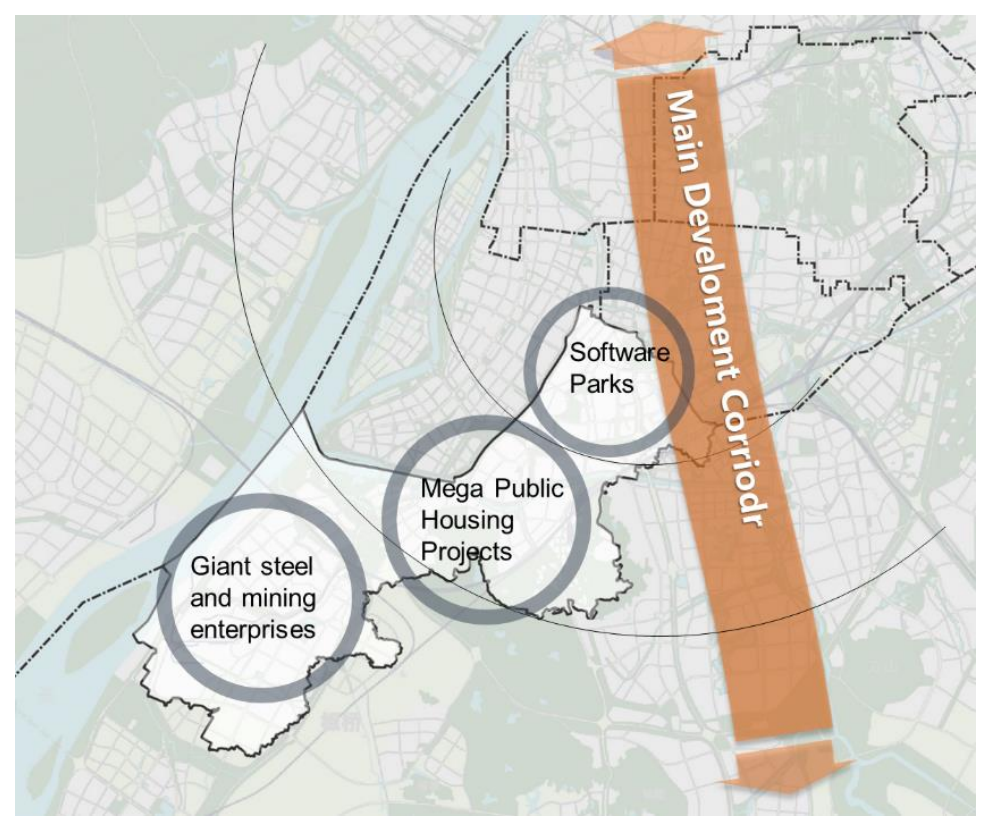

Figure 2 Location and status-quo functional zone of Yuhuatai 


\subsection{Desakota Land use Pattern and extreme nonequilibrium infrastructure supply}

The overall land use of Yuhuatai District is a typical desakota pattern where urban and rural lands coexist and intertwined and strip-shaped sprawl alongside arterial and communication roads. The traffic network of the entire district is not complete, mainly relying on the radial trafficway start from the central city to the fringe, so the newly constructions including the residential areas, industrial areas are distributed on thin layer of the trafficway but lacked indepth extension. This land use pattern has led to inefficient, fragmented land use. living land are mixed, which has a greater impact on the quality of life of residents. As weak-sided fringe, Yuhuatai District failed to attract the mass investment from the municipal government and public service supply on public transports, schools, hospitals, gyms or cultural facilities are extreme insufficient compared with the central city or strong-sided fringe. However, it become home to NIMBY facilities, such as large indemnificatory housings, large overpasses, building materials markets and cemeteries which occupied lots of land and may have negative impacts on surrounding area.

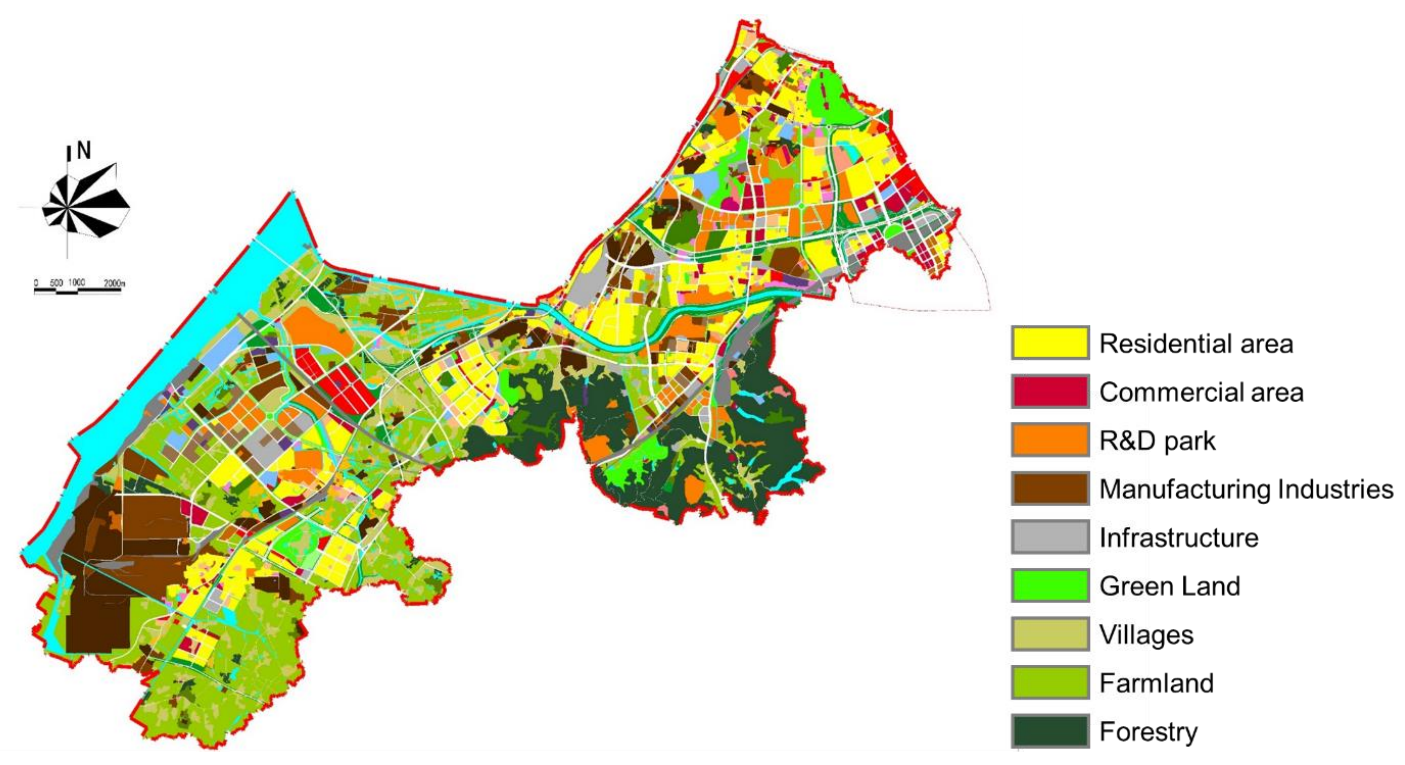

Figure 3 Land use status-quo of Yuhuatai District

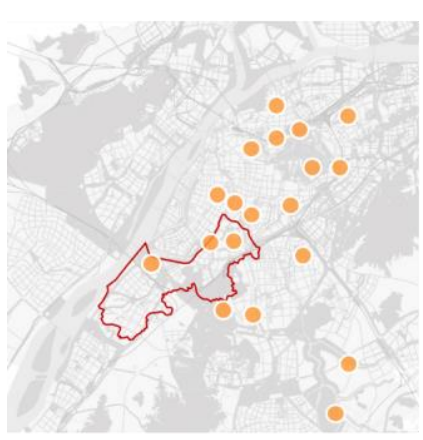

large overpasses

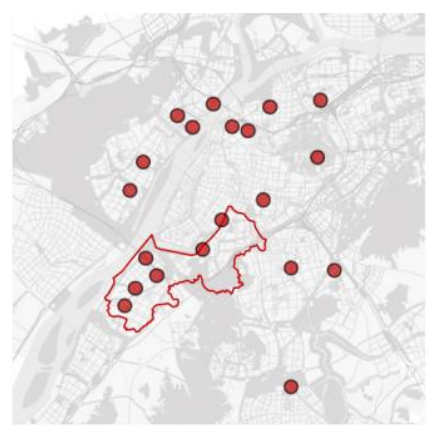

building materials markets

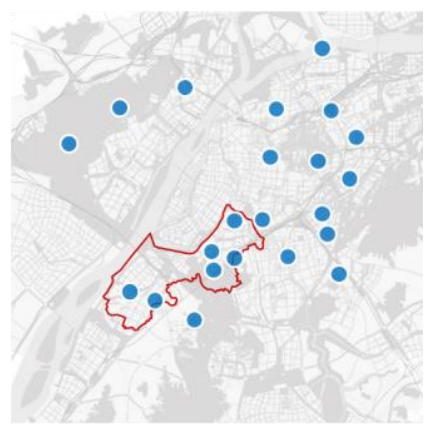

cemeteries

Figure 4 Distribution of the some kind of NIMBY facilities in NANJING 


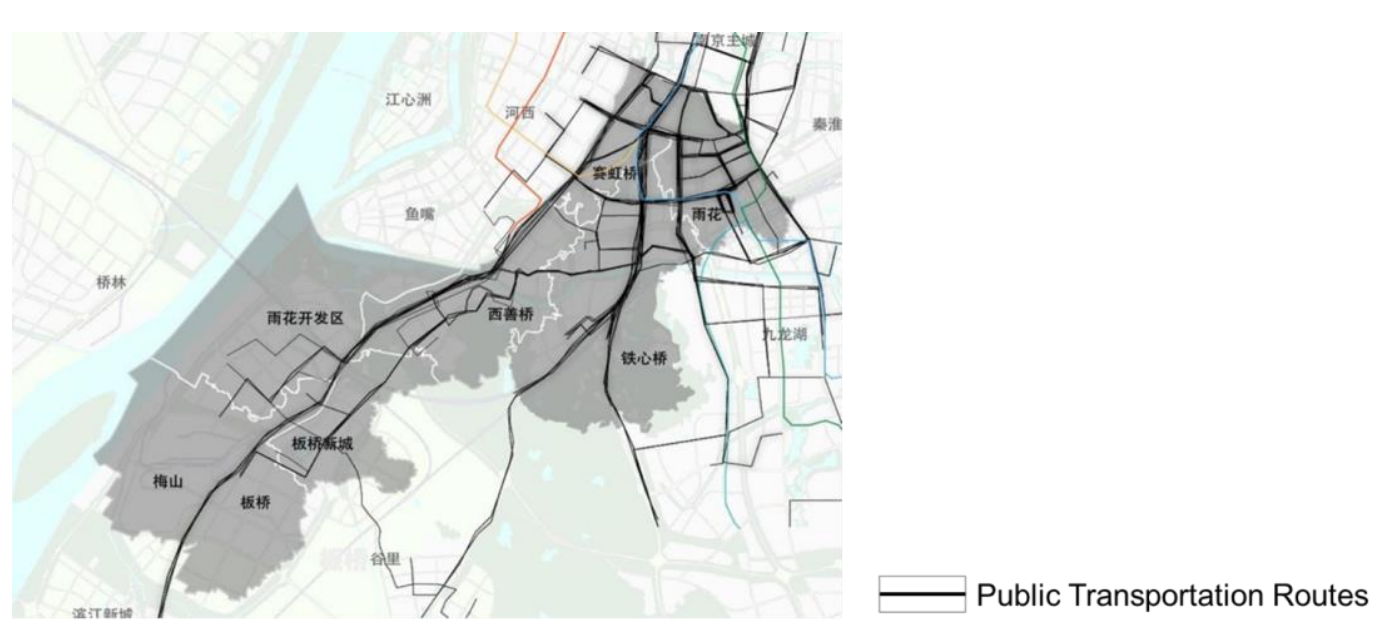

Figure 5 Distribution of the public transport routes of Yuhuatai District

\subsection{Adaptive administration strategy and fragmentated governance}

Not only the spatial change, but the power structure and governance behind is dynamic. Been regarded as reserve area of central city, Yuhuatai District undergone many administrative division adjustments, making room for the spatial expansion of the central city. To some extent, the 'fringe' should be defined by the dynamic change of the 'centralfringe' relationship, and the former fringe will become the future central city. Corresponding to the rapid urbanization and dynamic 'central-fringe' relationship, an adaptive spatial governance was formed. The adaptive adjustment strategy ensures the consistency of the development of urban fringe, which is an efficiency-first decision-making mechanism. However, the other side of the coin is its fragmentated sub-government power structure, which is caused by the coexistence of the normal government (e.g. town and street government) whose duty is social administration, and the quasi-government entity (e.g. administrative committee of economic development zone and new city) whose duty is economic growth. The two kinds of sub- government overlaps in administrative space but conflicts in the governance objectives and paths, resulting in the low-level redundant construction and disordered policy direction.
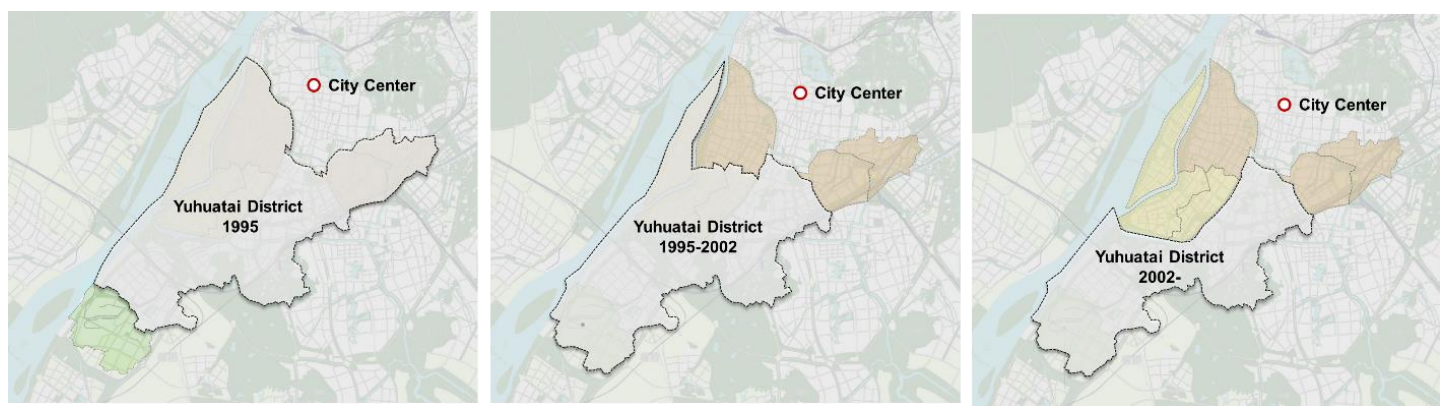

Figure 6 Changing of the administrative division of Yuhuatai District since 1995 


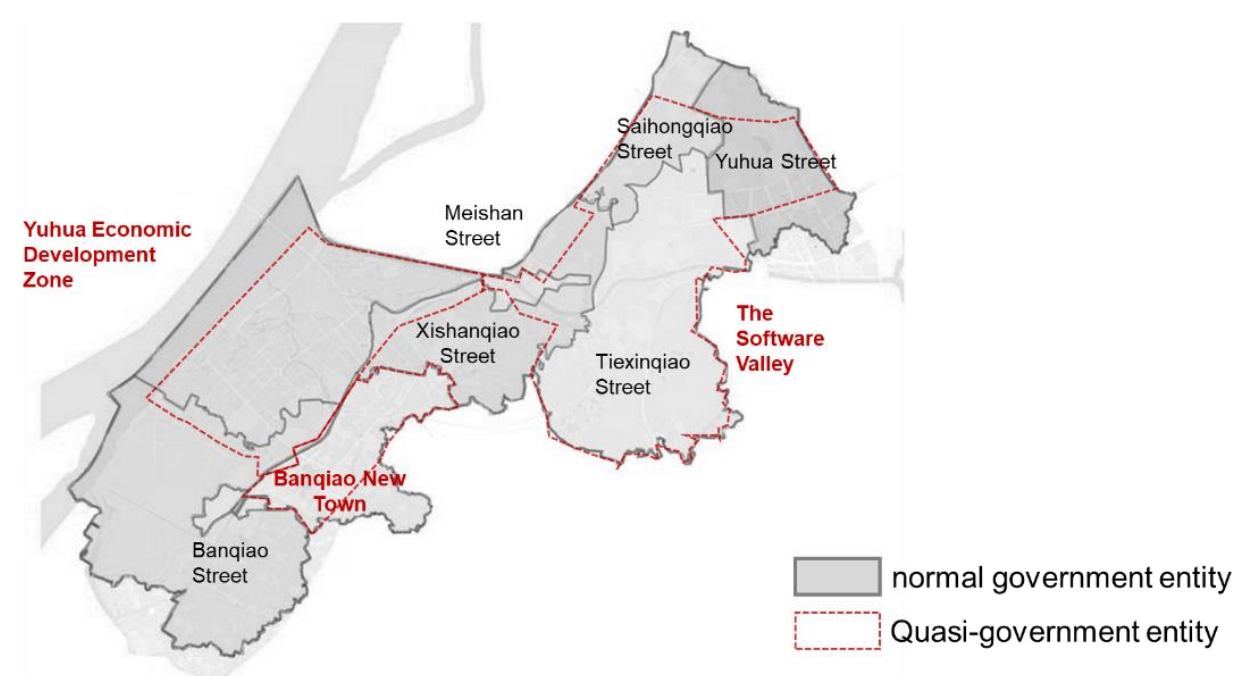

Figure 7 Division of normal government/quasi-government entity in sub-government level

\subsection{Leap-forward industrial involution and divided society}

Since the whole fringe is collaged by mega-projects or industrial giants in different times, the social structure tends to be polarized which makes the social integration become an important challenge. The two main social groups are the IT employees working in the Software Park and the public housing residents. The IT employees are young, well-educated and can earn higher income. Constantly, the residents in the public housing is aging, and many of them belong to vulnerable group who got unemployed live on the social assistance. The gather of low-income residents brings pressure on elderly care services, re-employment Public security service services. As for young IT employees the work-residence separation is obvious since the living conditions in Yuhuatai District cannot met their demands. Therefore, a large number of young people work here live in other districts, making the lack of urban vitality.

\section{Reaffirming the weak-sided urban fringe: new opportunity under new context and the hypothesis of flexible approach}

\subsection{Paradigm Shift: Modernization 1.0 to 2.0}

The characteristics of modernization in the past 40 years of China are quantitative economy and government's enterpriseization. As the economic system reform greatly stimulated the social demand, the 'quantitative economy' strategy is adopted to fill the gap between the demand and the low supply levels of the planned period (as well as the gap between unbalanced regional development) through increasing the productive quantity (e.g. GDP, FDI, etc.), as fast as possible. On the other hand, the GDP competition between cities made the local government set the economic growth as the top priority and the government itself become the biggest 'enterprise', which is described by David Harvey as the 'neoliberalism with Chinese characteristics'. In this way the modernization 1.0 mode was formed, which is characterized by quantitative-prior industrial development and rapid expansion of urban fringe.

Marked by the global financial crisis in 2008, the global economic structure is undergoing profound changes. After 30 years of rapid industrialization, the demand on quality-prior 
development replaced the demand on quantity economy, thus the path dependence of the modernization 1.0 came to an end, giving way to the modernization 2.0 or the 'the New Normal' era according to the government discourse. The modernization 2.0 is distinct with its former version in many aspects, including the oversupply in normal products (rather than shortage in supply), the quality-prior economy (rather than quantity-prior economy), the endogenous development mode (rather than exogenous development mode), the comprehensive competition on both industries and services (rather than single economic competition on manufacturing), the post-Fordism social production (rather than the Fordism standard products) and so on.

Modernization1.0 $\rightarrow$ Modernization 2.0

\begin{tabular}{rl|l|l|}
\cline { 3 - 4 } Fast Growth & $\rightarrow$ & Stable Increase \\
Products Economy & $\rightarrow$ & Consumption Economy \\
Manufacture & $\rightarrow$ & Service Industries and New Economy \\
Quantity-prior & $\rightarrow$ & Quality-prior \\
Fordism & $\rightarrow$ & Post-Fordism \\
GDP Competition & $\rightarrow$ & Comprehensive Competition \\
Government Dominant & $\rightarrow$ & Market Dominant \\
\end{tabular}

Figure 8 Connotations of the paradigm shift from modernization 1.0 to 2.0

\subsection{New opportunities for weak-sided fringe in modernization $\mathbf{2 . 0}$}

As mentioned above, the differentiation between the strong-sided and the weak-sided urban fringe lies in the different interrelationship with the urban development axis/ corridors, and stemmed from the paradigm of modernization. At present, with the continuous changes and restructuring of the region, the weak-sided urban fringe has also confronted with new development opportunities. On the one hand, with the evolution of transportation and information technology, the city-region has changed from hierarchy system to network, and new regional connections may be formed, thus giving weak-sided fringe like Yuhuatai District the chance to link to the new urban or regional development axis/ corridors. On the other hand, the goals of urban development change from monism to pluralism. In the modernization 1.0, the city emphases on economic growth, therefore mega-projects, large industrial zone and transportation hubs which exert directly affect on the growth of GDP become core resources and be placed in the strong-sided fringe. Under the current new context, the value judgment on resources begun for fringe development to diversify, extending to ecology, innovation, culture, leisure, etc. As a result, the weak-sided fringe faces new opportunities for further development.

\subsection{Planning Methodology: flexible reconstruction, structure control and action-oriented approaches}

Despite the new development opportunities, it does not mean that the weak-sided fringe can become the strong-sided one at one move. Currently China's urbanization has entered a quality prior, slower speed and market-driven phase after 40 years of rapid, hyper-dynamic and government-driven urbanization, and the general spatial structure and pattern of China's cities tends to be stable, in this way, the weak-sided fringe will remain the status of lacking core resources at least in the initial stage (after the accumulation of development it 
is possible to undertake core resources). What is more, in the modernization 2.0 , due to the deceleration in economic growth, it is impossible to duplicate the growthism-oriented 'rigid' development and planning approach as the strong-sided fringe did in the modernization 1.0 era. Therefore, a flexible planning approach is required.

"Flexible" means affordable and sustainable, and it differs from the 'rigid' construction in terms of space, function and governance. In terms of spatial development, it will mainly rely on the integration, optimization or redevelopment of old urban space with very few incremental lands. In terms of function, the weak-sided fringe should not be an independent growth pole, but need to cooperate with the central area, to undertake the spill over resources of the central area and final become an indivisible plate of the city-region. And in terms of governance, the strong government dominant is difficult to achieve in the development of the weak-sided fringe, but it still needs the government to carry out limited but precise guidance and integrate existing dispersed entities.

In summary, the context shift of from 'building city upon blank land' to 'building city upon city' requires a different altitude in dealing with the ideal vision and the status-quo, and the key challenge is only not how to active the weak-sided fringe through a restrain but precise planning approach, but how to integrate the weak-sided fringe with the current loose, unordered, modernization characterized strong-sided fringe which formed mass through investment and coherently form a powerful overall structure of the city.

Table 1 Comparison between the rigid construction of strong-sided fringe and the flexible reconstruction of weak-sided fringe

\begin{tabular}{|l|l|l|}
\hline & $\begin{array}{l}\text { The Rigid Construction of Strong- } \\
\text { sided Fringe }\end{array}$ & $\begin{array}{l}\text { The Flexible Reconstruction of Weak- } \\
\text { sided Fringe }\end{array}$ \\
\hline Space & $\begin{array}{l}\text { Highly Urbanized } \\
\text { Spawl from the central city } \\
\text { Building city upon blank land }\end{array}$ & $\begin{array}{l}\text { Incomplete urbanization; } \\
\text { Smart organic growth; } \\
\text { Good ecological environment; } \\
\text { Based on space renewal and structural } \\
\text { optimization }\end{array}$ \\
\hline Function & $\begin{array}{l}\text { Undertake urban quality industry } \\
\text { Compound function }\end{array}$ & $\begin{array}{l}\text { Specialized functional nodes such as } \\
\text { ecology, R\&D and tourism }\end{array}$ \\
\hline Governance & $\begin{array}{l}\text { Government dominant; weak } \\
\text { bottom-up self-organization }\end{array}$ & $\begin{array}{l}\text { Market dominant; strong bottom-up self- } \\
\text { organization }\end{array}$ \\
\hline
\end{tabular}

\section{Case Study: Strategic Plan of Yuhuatai District}

\subsection{Ideal Vision: Flexible Specialized Embedded Structure}

The methodology of planning is a challenging problem. As for strategic spatial plan there is also a lack of the best or only method of formulation. An important symposium classifies the researches on strategic spatial plan into three categories, thus the institutional, communicative/discourse and interactive approaches, which indicates the mainstream cognition of strategic planning methodology; Albrechts briefly proposed a four-track approach, including long-term vision, long-term and short-term actions, contact with stakeholders and basic process with citizens. Jean Hillier believes that transitional, potential, 
and flexible post-structural methodology is a method to solve China's strategic planning. The above combing shows common attempt to make a simple, clear and understandable structure without losing flexibility and systemic. In view of this, this paper considers that a possible strategic planning structure consists of two parts: structure control and action.

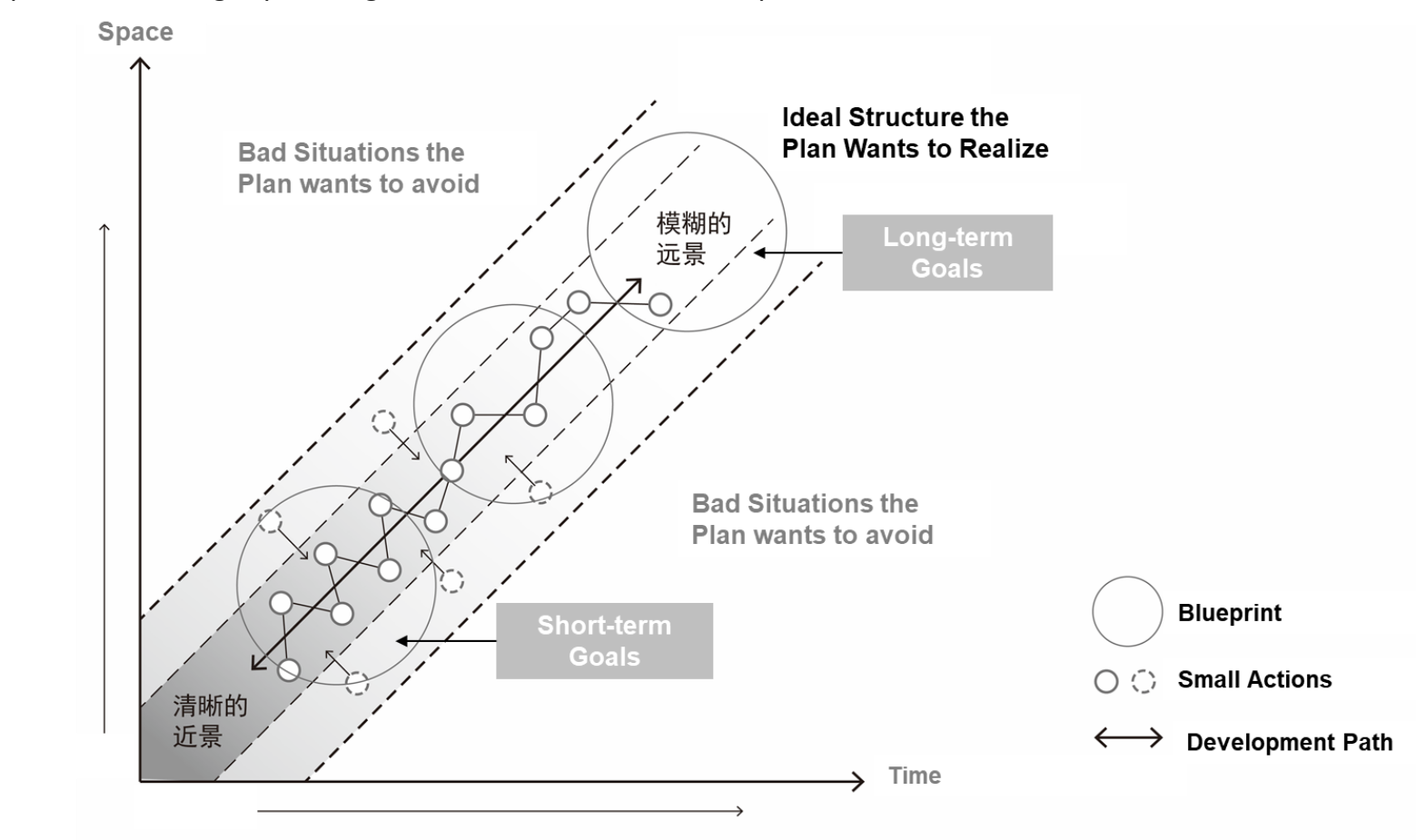

Figure 9 Topography of China's strategic plan

\subsection{Structure Control: From Re-create to Re-connect: precise repair to existing socio-spatial structure.}

The local Jiangnan Region (means south of the Yangtze River) excellent natural context, history and culture, relatively sustained incremental potential provides another possible solution for the transformation and upgrading of weak-sided fringe in the new macro development stage., the re-connecting solutions. Based on blue network, green network and grey (transportation and infrastructure) network, combined with functional quality organic upgrade and spatial scale shrewd, the plan attempts to constructing high-quality network integrated functional area, and realizing the systematic improvement of the entire structure. With the reconnection of urban space with green/blue/grey Network, the reconnection of social-spatial relationship and the reweaving of the fragmented governance, the plan realizes the restrain but precise intervene to the current space, which lead to the maximum of entire regional effect. 

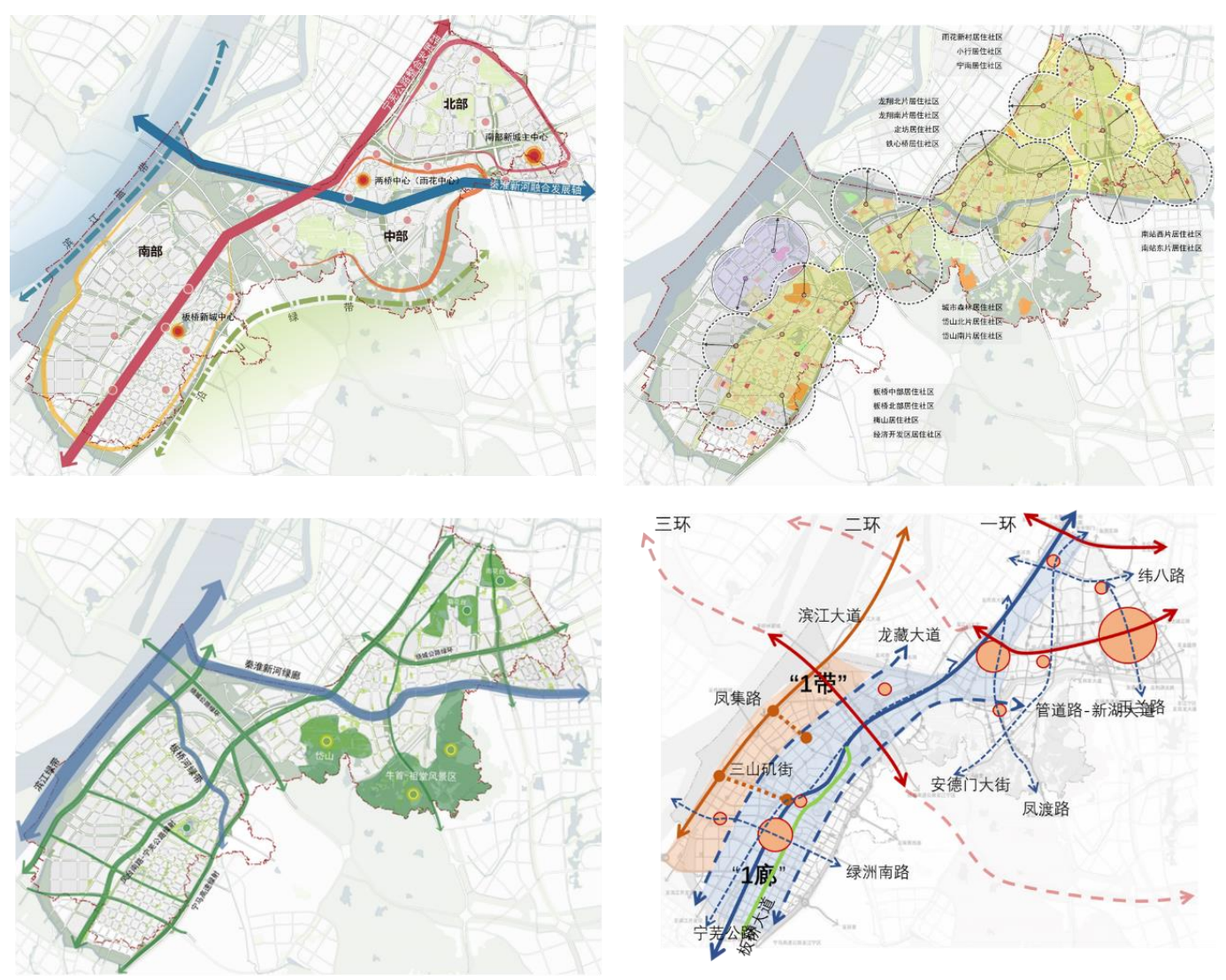

Figure 10 Reconnection and precise repair to existing socio-spatial structure

\subsection{Action: Progressive Smart and Organic Growth}

The development path of the modernization 1.0 period seems to be self-evident: urban space can be produced and duplicated through a very fast and easy way soon become reality. In this way the only task of strategic plan is the 'blueprint', and it required no attention to think about the action or realization of the plan. However, in the modernization 2.0 era, the plan should focus on helping realizing the blueprint or structure on step by another. In the case of the Yuhuatai, the action logic of strategic planning mainly presents the following characteristics:

Rooted development. Get rid of a single exogenous path dependence, seek to adapt to the new normal macro-development needs, endogenous exogenous compatibility, and develop a local development model by rooting local culture, society, space and other conditions;

Delicate development: Guide the smart growth, build exquisite space and promote lean economic development in the first big situation of large projects. Pay attention to the efficiency and efficiency of input, that is, by investing in key "points", realize self-efficiency and derivative benefits, comprehensive benefits, and maximize system benefits, and guide the rest to self-evolution. 


\section{Conclusion}

As the macro environment enters the "new normal", strategic planning is also facing transformation and upgrading. Starting from Yuhuatai, we seem to see a new paradigm that differs from traditional strategic planning. Is our goal to create a new paradigm to replace the old paradigm? Not exactly. Paradigm can be seen as a possible approach or solution under a certain period of time or contexts, and the reason why strong-sided fringe development well in the past 40 years is not because of some certain paradigm, but because the paradigm chosen best met the modernization 1.0 context. Therefore, when faced with the macro-transformation of modernization 2.0, the pursuit of good planning and correct knowledge is the only possible eternal paradigm of strategic planning.

\section{References}

Albrechts, L. (2004). Strategic (spatial) planning reexamined. Environment and Planning B: Planning and design, 31(5), 743-758.

Harvey, D. (2007).A brief history of neoliberalism. Oxford, UK, the Oxford University Press.

Healey, P., \& Underwood, J. (1978). Professional ideals and planning practice: a report on research into planners' ideas in practice in London Borough planning Yeh, A. G. O., \& Wu, F. (1999). The transformation of the urban planning system in China from a centrally-planned to transitional economy. Progress in planning, 51(3), 167-252.

Innes, J. E. (1995). Planning theory's emerging paradigm: Communicative action and interactive practice. Journal of planning education and research, 14(3), 183-189.

Leaf, M. (1998). Urban planning and urban reality under Chinese economic reforms. Journal of Planning Education and Research, 18(2), 145-153.

departments. Progress in planning, 9, 73-127.

Wu, F., \& Zhang, J. (2007). Planning the competitive city-region: The emergence of strategic development plan in China. Urban Affairs Review, 42(5), 714-740. 